\title{
retrato de anarda ou a lira aguda de manuel botelho de oliveira
}

\section{Jean Pierre Chauvin*}

" Professor de "Cultura e Literatura Brasileira" na ECA - USP. E-mail para contato: tupiano@usp.br
"Se eu podesse desamar/a quen me sempre desamou" (Pero da Ponte, Séc. XIII)

"Trovomni Amor del tutto disarmato" (Francesco Petrarca, Séc. XIV)2

"Que quanto mais vos pago, mais vos devo" (Luís Vaz de Camões, Séc. XVI) ${ }^{3}$

\section{Resumo}

Publicada pela primeira vez em 1705, Música do parnaso foi reeditada apenas no século XX. Este hiato de tempo dificultou o acesso dos leitores e parece vincular-se a uma concepção de literatura nacionalista, que passou a vigorar no final do século XVIII e foi intensificada durante o nosso Romantismo. Neste trabalho, propõe-se a análise de algumas liras de Manuel Botelho de Oliveira, 


\section{opiniães}

considerando aspectos relacionados à poética seiscentista.

\section{Palavras-chave:}

Manuel Botelho de Oliveira; Música do Parnaso; Poética.

\section{Abstract}

Música do parnaso was published in 1705 and it was reissued only in the twentieth century. This long period out of circulation seems to be related to a nationalist literature conception in the late eighteenth century, that was intensified during the Brazilian Romanticism and made the access to this book difficult to readers. In this article we propose to analyze a few Manuel Botelho de Oliveira's poems, considering aspects related to the seventeenth-century's poetic.

\section{Keywords:}

Manuel Botelho de Oliveira; Música do Parnaso; Poetic.

\section{Resgate}

Apesar da qualidade inconteste dos sonetos de Manuel Botelho de Oliveira (1636-1711), durante muito tempo seu nome foi quase totalmente esquecido, tanto por parte dos historiadores quanto por uma considerável parcela dentre os críticos literários e, por irradição, dos manuais voltados ao ensino médio - muitos deles concebidos em prol da indústria facilitadora do vestibular - , que vivem a reproduzir mais do mesmo.

Sob essa ótica, é algo sintomático que Música do Parnaso tenha sido reeditado somente no século $X X$, mais de duas centúrias após a primeira edição do livro, em 1705, pelas mãos do impressor português Miguel
Manescal.

No estudo introdutório que faz a um conjunto de poemas publicados no século XVIII, João Adolfo Hansen sugere que a depreciação dos poetas etiquetados como "barrocos", em que Manuel Botelho de Oliveira foi viva e implacavelmente associado, teve origens nos Setecentos. O crítico observou que:

Em Portugal, a obra dos seiscentistas começou a ser desqualificada principalmente a partir das reformas da cultura patrocinadas por Sebastião de Carvalho e Melo, Marquês de Pombal. As reformas combatiam o aristotelismo das instituições de ensino controladas pelos jesuítas e as letras do século XVII foram então associadas ao "doloso systema de ignorancia artificial" (HANSEN, 2002, p. 22).

Adma Fadul Muhana (2005) e Ivan Teixeira (2005) corroboraram a hipótese de Hansen ao detectar, em nossa "crítica tradicional", a permanência de "pressupostos romântico-nacionalistas, a desprestigiar a poesia de Botelho de Oliveira, sob pretexto de que lhe faltam singularidade expressiva e integração com a realidade do país", como seria o caso de "Joaquim Norberto de Sousa Silva [Bosquejo da História da poesia brasileira], Cônego Fernandes Pinheiro [Resumo de História Literária], Sílvio Romero [História da literatura brasileira], José Veríssimo [História da literatura brasileira: de Bento Teixeira (1601) a Machado de Assis (1908)] e Ronald de Carvalho [Pequena história da literatura brasileira], entre outros" (TEIXEIRA, 2005, p. 33-34).

Dito de modo mais objetivo, Manuel Botelho de Oliveira foi injustamente depreciado por um grupo de homens poderosos a capitanear uma crítica de ótica provinciana e orientada por critérios localistas, e que 
se recusavam a enxergar a produção de outros tempos em acordo com as preceptivas, as formas e os pressupostos das épocas em que os textos eram produzidos e onde circulavam.

Em outras palavras, graças ao empenho de uma parcela da crítica, o poeta tornou-se uma espécie de mito negativo de nossos espaços de circulação: sorte de artefato cultural falso e remoto, a que se precisa chegar por meio de novos modos de aproximação, que levem em conta o ambiente de composição e a cultura oral de sua época.

Esses métodos seriam certamente muito diversos em relação àqueles propalados pelo poeta e historiador Gonçalves de Magalhães. Em 1836, ele afirmava que "a maioria dos autores coloniais ficaram alienados do éthos nacional no artificialismo da imitação de modelos metropolitanos" (HANSEN, 2002, p. 25).

No Verdadeiro método de estudar, publicado em Portugal clandestinamente no ano de 1746, o português Luís António Verney (1713-1792) mostrava-se claramente contrário à poética seiscentista. Na "Carta Sétima", ele tripudia sobre as lições de Baltasar Gracián, como forma de estender suas censuras à produção de poesia durante o século XVII:

Li há anos um livrinho pequeno de um espanhol, que cuido era Gracián [...]. Lembro-me que o autor, no prólogo, desejava ao livro a boa fortuna de cair em mãos de quem o entendessem. Pelos meus pecados, eu fui um dos que não se cansaram em entendê-lo, porque logo entendi que o livro não merecia que se lesse (VERNEY, 1991, p. 137).

Avancemos. Na célebre Apresentação da poesia brasileira, reconhecida obra de fôlego publicada originalmente em 1946, Manuel Bandeira desfaz tanto a qualidade de Gregório de Matos e Guerra quanto a de Manuel BoteIho de Oliveira, assumindo um tom de cunho sumário, e mesmo arrogante, que em muito relembra o sabor amargo dos críticos oitocentistas:

\begin{abstract}
A importância de Gregório de Matos lhe advém da parte satírica de sua obra, a primeira que reflete em versos a sociedade da colônia, com o seu mestiçamento, o parasitismo português, os desmandos sexuais e outros males. Não foi um grande poeta, mas era uma personalidade forte, a primeira que assim se afirmava no Brasil, onde a sua posição corresponde proximamente à de Juan de Caviedes, no Peru. Ao lado dele mal se pode lembrar o nome de Manuel BoteIho de Oliveira, autor de um medíocre poema descritivo intitulado A llha da Maré, cujo único mérito está em inaugurar o louvor do país em nossa poesia" (BANDEIRA, 2009, p. 14-15).
\end{abstract}

Mas vinte anos antes, Mário de Andrade - aquele que seria canonizado, ainda em vida, como nosso maior representante da estética modernista - repudiava o estilo na poesia de Luis de Góngora y Argote (1561-1627). ${ }^{4}$

Como se sabe, graves foram as consequências advindas da falta de uma avaliação menos preconceituosa e anacrônica por parte de uma crítica que desferiu violentos golpes contra o suposto artificialismo dos versos de Música do Parnaso. Um resquício disso pode ser visto nas palavras de Antonio Candido, apostas em um breve manual publicado no final da década de 1990:

A esse espírito entre devoto e cortesão se vincula um escritor de certo interesse, Manuel Botelho de Oliveira, exemplo típico do falseamento a que chegou o espírito barroco 


\section{opiniães}

nos seus aspectos menores, quando a argúcia virou pedantismo 5 e a sutileza um mero exibicionismo, dando a impressão de que a palavra rodava em falso, à procura de nada (CANDIDO, 1997, p. 24). ${ }^{6}$

De maneira geral, as apreciações a respeito do poeta são quase sempre pautadas pela brevidade dos exames e pela postura ora relativamente favorável, ora francamente negativa, em que são traçados perfis pejorativos do poeta e de sua produção de caráter supostamente artificial e pernóstico.

Felizmente, outras vozes contrabalançaram a recepção ao legado de Manuel Botelho de Oliveira. Na História concisa da literatura brasileira, Alfredo Bosi revela-se como sendo um dos primeiros a reposicionar a visão mais condescendente a respeito da poesia de Manuel Botelho de Oliveira.

Dialogando com um ensaio publicado por Eugênio Gomes originalmente em 1987 (que mais enaltecera o poema Ilha da Maré), Bosi afirma estarmos "diante de um poeta-literato stricto sensu, capaz de escrever com igual perícia em quatro idiomas e nas várias formas fixas herdadas aos trovadores e aos renascentistas [...] [cujo] virtuosismo apela abertamente para os modelos da época" (BOSI, 2001, p. 41).

Em 1977, José Guilherme Merquior enfatizaria a filiação de Música do Parnaso à tradição poética dos poetas espanhóis e italianos, sendo uma obra "Colocada sob o signo de Góngora e Marino [...] Lírica onde as convenções petrarquistas [...] e a excepcional acuidade das imagens visuais se articulam em engenhosos parelelismos sintáticos, estofados de expressões de significação ora convergente, ora divergente e antitética" (MER-
Tendendo para lados opostos, o fato é que a polarização de uns e outros não auxiliou em nada no resgate do autor e da adequada avaliação de seus versos. Além de contribuir para a cristalização de uma injusta e depreciativa imagem do poeta e, por extensão, de outros escritores de seu tempo (basicamente, todos aqueles do século XVII) o fato é que o livro capital de Manuel BoteIho de Oliveira só seria reeditado em raras ocasiões, no Brasil: todas elas no século XX.

A primeira delas só se concretizou de modo parcial, chancelada pela Academia Brasileira de Letras, em uma breve antologia contendo apenas as rimas portuguesas - organizada por Afrânio Peixoto (1929).

A segunda edição transcorreu sob a responsabilidade de Antenor Nascentes, que escreveu brevíssimo estudo relativamente favorável na edição do Instituto Nacional do Livro (1953, sucedida por uma reedição, publicada pela Ediouro em 1967).

Deve-se mencionar a cuidadosa preparação conduzida por Adma Fadul Muhana, editada pela Martins Fontes em 2005 - mesmo ano em que foi lançada a versão facsimilar do livro, anotada por Ivan Prado Teixeira e publicada pela Ateliê Editorial. A ocasião foi propícia, aliás, para se comemorar o tricentenário da primeira edição da Música do Parnaso em Portugal.

Caberia lembrar que no início do século XVIII, publicar uma obra não era tarefa de somenos importância. Ela implicava o envio dos originais para a oficina tipográfica, antecedida pela concessão de licença do Santo Ofício, complementada pela autorização de sua publicação por pessoas autorizadas diretamente pelo Rei.

Obedecendo aos trâmites de seu tempo e o entre-lugar da província da Bahia no universo luso-brasileiro, 
Música do parnaso levou quase dois anos para ser publicado, tendo sido remetido por Manuel Botelho de Oliveira a Portugal em 1703.

\section{Paratextos}

Dando sequência procedimental, e até certo ponto protocolar, à generosa e majestática dedicatória que escreve para Dom Nuno Álvares Pereira de Melo - seção em que Manuel Botelho de Oliveira enfatiza as adversidades representadas pelos "bárbaros índios" e do continente americano, "inculta habitação" (OLIVEIRA, 1953, p. 3) -, o poeta compõe um Prólogo mais enxuto, devidamente enquadrado pelo subtítulo "Ao leitor", que traz o discurso, antes sublime, de volta ao plano da medíocre da terra.

A alternância de estilos elevado e mediano entre as seções pode ser considerada como uma deferência da parte de Manuel Botelho de Oliveira aos preceitos de Horácio (65-8 a.C.) e Longino (213?-273). De acordo com o que dizia o primeiro: "é de justiça, em determinadas matérias, consentir com o mediano e o tolerável" (HORÁCIO, 2010, p. 66).

Isso parece confirmar a imitação de modelos e a aplicação de preceitos contidos nos antigos tratados da arte poética. Para Longino, "Nos discursos, pois, o patético e o sublime, mais aproximados de nossa alma, graças a uma afinidade natural e ao brilho, sempre se mostram antes das figuras, obumbrando e mantendo encoberto o artifício destas" (LONGINO, 2010, p. 91).

Substancialmente, os paratextos ("Dedicatória" e "Prólogo") que antecedem o coro de rimas atendem a uma demanda não só estética, mas também política, vigente entre os séculos XVII e XVIII: a de produzir textos com características que o aproximassem do encômio. Ou seja, quando compõe sua Música do Parnaso, publicada originalmente em 1705, Manuel Botelho de Oliveira aplica ao texto uma antiga lição da retórica.

A "Dedicatória" também pode ser compreendida como uma variante do gênero epidítico, uma vez que cumpre a dupla função de elogiar o destinatário do livro, elevando-o para a posição mais alta e poderosa no Império português, além de captar-Ihe a autorização e patrocínio para a publicação de seus versos.

Outro fator muito importante o corrobora: a "Dedicatória" ganha maior pujança e força quando comparada ao paratexto seguinte, reservado ao leitor. Ou seja, o poeta concilia matérias, gêneros e estilos diferentes para cada texto que antecede os poemas.

Note-se que a "Dedicatória" tem por sujeito o Primeiro Duque de Cadaval, matéria evidentemente nobre e que, portanto, comporta e justifica o emprego do gênero elevado (adequação entre matéria e gênero) e o estilo humilde, afetado pelo versejador, pois se coloca em posição inferior ao homenageado. Conforme assinalou Ivan Teixeira:

[...] a retórica tradicional entende a dedicatória como manifestação do gênero exornativo de discurso, tomado como sinônimo de deliberativo ou epidítico, por meio do qual o orador louva ou censura a matéria de sua invenção. Assim, pelos preceitos retóricos do tempo, a dedicatória de um livro deveria exaltar aquele que, com a autoridade de sua posição na hierarquia do Estado, protegesse a obra contra a malícia dos maus leitores (TEIXEIRA, 2005, P.15).

Em severo contraste com a primeira seção do livro, o "Prólogo" revela outra face de Manuel Botelho de 


\section{opiniães}

Oliveira, em que ele abandona o elogio à autoridade política e passa à explicação prévia do que se vai ler. Aqui ele está a falar para pessoas de condição igual ou inferior.

Isso também explicaria o fato de ele ter sido escrito de modo mais objetivo, ou seja, estilisticamente casado ao caráter da persona autoral, beirando o didático: "ofereço neste lugar, para que se entenda que pode uma só Musa cantar com diversas vozes". Repare-se que o poeta afeta conduzir o leitor, antecipando-lhe as divisões dos versos e sua expressão de outrora: "No princípio celebra-se uma dama com o nome de Anarda, estilo antigo de alguns poetas".

Ora, como salientava Ivan Teixeira, a poesia é um "evento cultural, que partilha de discursos sociais específicos, com normas próprias de invenção, de escritura e de circulação". Assim, é preciso "recompor, ainda que parcialmente, o sistema de referências segundo o qual o artista escrevia, sem o que se torna difícil sustentar uma visão histórica do fenômeno poético" (TEIXEIRA, 2005, p. 12).

No que diz respeito ao que afirma o poeta em seu "Prólogo", talvez o mais importante seja dito nas linhas em que parecem ressoar as palavras de Baltasar Gracián, "la variedad, gran madre de la belleza" (GRACIÁN, 2010, p. 136). Eis como Manuel Botelho de Oliveira aborda o mesmo assunto: "assim como a natureza se preza da variedade ${ }^{8}$ para a fermosura das cousas criadas, assim também o entendimento a deseja, para tirar o tédio da lição dos livros" (OLIVEIRA, 1953, p. 9).

Tanto as coisas naturais (lira $=$ emoção $=$ espontaneidade) como aquelas que se prendem ao artifício (entendimento $=$ razão $=$ cálculo) entram em poderosas analogias, o que sugere o diálogo dos pressupostos aplicados pelo poeta com os preceitos constantes dos manuais de seu tempo - em particular o Tratado de agudeza e engenho, publicado por Baltasar Gracián em 1642, para quem "La Semejança es origen de una inmensidad conceptuosa" (GRACIÁN, 2010, p. 180).

Vale lembrar que a palavra entendimento comparece muitas vezes ao manual do padre espanhol. Em seu tratado ela está relacionada a outra analogia fundamental segundo a ótica do conceptismo, uma vez que o conceito é recurso que mais agrada o entendimento: "Entendimiento sin Conceptos es Sol sin rayos" (GRACIÁN, 2010, p. 137).

Podemos supor ainda que, tanto nos paratextos ("Dedicatória" e "Prólogo") quanto nos poemas de Música do Parnaso, Manuel Botelho de Oliveira pretendesse estabelecer uma forte ligação histórica e cultural com os temas e preceitos de tempos muito anteriores ao seu.

Isso nos levaria a considerar que Música do Parnaso permite o diálogo com as Poéticas de Aristóteles (escrita quatro séculos antes de Cristo), de Horácio (um século antes de Cristo) e de Longino (século III), além da alusão a determinados temas e gêneros poéticos cultivados pelos poetas portugueses da Idade Média, mas também por Petrarca (século XIV) e, especialmente, os versos legados por Luís Vaz de Camões, no final do século XVI.

A consciência entre a matéria, a expressão e a forma é um pressuposto assinalado pelo próprio poeta, que define seu ofício desta forma: "Poesia não é mais que um canto poético, ligando-se as vozes com certas medidas para consonância do metro" (OLIVEIRA, 1953, p. 9). Eis aí a confirmação de que, em seu caso, as vozes que entoam sua lírica ${ }^{9}$ sejam a contraparte do artifício, da técnica de composição em verso. 


\section{Rimas da Agudeza}

Elemento que diz respeito à sonoridade, a consonância a que o poeta se refere no "Prólogo" ganha nova amplitude nos versos, mesmo porque ela se espraia infalivelmente nos vinte sonetos que dedica a Anarda - sorte de musa inspiradora, ainda que em carne e osso: uma figura de "candores" e "impia" que "pode dar" ao "rude discurso [do poeta] cultas flores" (Anarda Invocada, p. 12).

O cruzamento semântico de palavras localizadas em versos alternados é uma das tônicas dos sonetos. O que se entenderia, hoje, por "rude discurso"? Discurso simplório, feito pelo homem bruto? O que se depreende de "cultas flores"? Flores que foram tratadas com cuidado pela beleza da "ímpia" e amada Anarda?

De fato, Anarda é pintada em condição superior e distante do eu-lírico. Não por acaso, o segundo soneto traz o título "Persuade a Anarda que ame", o que volta a sugerir o dado artificial que envolve o discurso lírico. Em Manuel Botelho de Oliveira, os afetos casam-se à razão que preside a fala.

O que poderia redundar em poesia piegas, com vistas a melhor representar o eventual desvario do poeta, não ultrapassa os contornos da forma (rimas, métricas e ritmo) e do gênero (soneto). A matéria (amor, saudade, distância) está acomodada, portanto, à forma e ao gênero. Ao adequar matéria, estilo e gênero, o poeta revela a cuidadosa aplicação dos preceitos poéticos não exclusivos de seu tempo, o que não impede reconhecer a qualidade estética de seus versos.

Assim como Camões sugeria "transforma[r]-se o amador na cousa amada" (CAMÕES, 1963, p. 107), a persona poética de Botelho incita a Anarda para que sinta e sofra em seu lugar: "Avivas em teu peito o meu tormento,/ Derramas por teus olhos o meu pranto" (Ponderação das lágrimas de Anarda, p. 13).

Os sonetos não apenas evocam o nome da mulher, sugerida como mulher amada. O gênero em si favorece uma composição estruturada em comparações, quase sempre reservadas aos quartetos. O poeta parece seguir a lição de Baltasar Gracián de que "Alcança el nombre su conveniencia con la cosa denominada, no menos que las causas y efectos della" (GRACIÁN, 2010, p. 266)

Ao justapor Anarda ao sol, mas também ao cév e às flores, cumpre ao poeta - cioso de imitar os arroubos de um eu apaixonado -, sugerir que "fermosura" da muIher que retrata seja equivalente ou mesmo superior aos encantos da natureza: "Pinta maios o sol, Anarda maios" (Sol e Anarda, p. 14). Consideremos o poema seguinte:

\section{Mostra-se que a fermosura esquiva não pode ser amada}

A pedra ímã, que em qualidade oculta Naturalmente atrai o ferro impuro, Se não vê do diamante o lustre puro, Prende do ferro a simpatia inculta.

Porém logo a virtude dificulta, Quando se ajunta c'o diamante duro: Que um ódio até nas pedras é seguro, Que até nas pedras uma inveja avulta.

Prendendo pois com atração formosa A formosura, qual Ímã se aviva, É diamante a dureza rigorosa; 


\section{opiniães}

Aquela junta com a dureza esquiva, Não logra a simpatia de amorosa, Perde a virtude logo de atrativa (OLIVEIRA, 1953, p. 14).

Isso permite dizer que algo de diferente acontece nesses versos, comparando-se àqueles em que se nota a costumeira presença de Anarda. No soneto, coisa rara, o poeta não menciona o nome da amada, embora possamos supor que dele também se trate, sob a forma da metáfora.

Eis uma composição que toma "A pedra ímã" como sujeito que atrai o "ferro impuro" por obra da natureza, do qual "prende a simpatia" não cultivada, não polida (como seria a beleza do diamante).

Na segunda estrofe, a virtude de atrair a "simpatia" não mantém a mesma integridade, o mesmo vigor quando a "pedra ímã" "se ajunta com o diamante duro", já que - apesar de simpáticas, as pedras são capazes de sentir "inveja" e "ódio".

Enquanto a "pedra ímã" atrai por obra da simpatia, o "diamante duro" é belo, mas esquivo. Portanto, a formosura "Perde a virtude longo de atrativa" se for dura como o diamante e não atraente como a "pedra ímã".

O sexto soneto traz uma engenhosa combinação entre o sentido da visão e da fala, ora contagiadas (o eu-lírico se diz "compelido") ora perturbadas (pelo "esquivo luzimento" e pelas "rosas" que "espinham") em acordo com os efeitos ora sugeridos, ora sofridos, pelo "cego deus" Cupido. Vejamos:

\section{Iras de Anarda Castigadas}

Do cedo deus, Anarda, compelido
Vejo teu rosto, e digo meu tormento;
Digo para favor do sentimento, Vejo para recreio do sentido;

As rosas de teu rosto desabrido, De teus olhos o esquivo luzimento: Este fulmina logo o raio isento Estas espinham logo ao deus Cupido.

Porém para experiências amorosas, Quando de amor as ânsias atropelas, As perfeições se mudam deslustrosas;

Porque tomando amor vingança delas, Nos rigores te afeia as lindas rosas, Nas iras te escurece as luzes belas (OLIVEIRA, 1953, p. 15).

Redobremos nossa atenção ao título. Quem sofre as duras consequências por sentir "Iras" em relação à Anarda é o próprio eu-lírico, que está a enfrentar os castigos descritos nas estrofes. Cupido faz com que a visão da amada faça-o expressar seu "tormento". Se a fala contribuiu com a maior intensidade do que ele já padece, a visão colabora com a motivação do que ele de melhor sente.

Observe-se que Anarda é retratada de modo a superar até mesmo as forças do deus do amor. Ela detém o britho esquivo do olhar e profere palavras duras a partir de seus lábios. Duas imagens invertidas se justapõem: a delicadeza da rosa não impede que as palavras firam como espinhos. A firmeza do olhar não impede que ele seja esquivo.

Desse modo, ao desviar-se daquele que a ama, é "o olhar esquivo" que "fulmina o raio isento", inocente, sincero e puro de Cupido. Já as palavras "espinham", ou seja, maltratam, barram, anulam a chegada do melífluo 
discurso amoroso. Essa ambivalência é uma constante na poética de Botelho de Oliveira: "o poeta intensifica a adoção equívoca dos vocábulos, seja por meio do trocadilho, seja por meio da calculada polissemia da frase, seja por meio da exploração de efeitos da luz e das cores sobre os afetos" (TEIXEIRA, 2005, p. 24).

A explicação para o emprego equivocado dos termos se encontra ainda uma vez na Arte de ingenio, Tratado de la agudeza: "La Primorosa equivocación es como una palabra de dos cortes, y un exprimir a dos luces. Consiste su artificio en encerrar debajo de una misma dicción dos significaciones" (GRACIÁN, 2010, p. 277).

Em meio à tempestade (outro sentido para o "tormento" reclamado pelo eu-lírico), resta ao poeta recorrer ao passado, às lições que pode tirar das "experiências amorosas". Afinal, quando os anseios, as expectativas são atingidas violentamente ("atropelados") pelo amor do presente, as cláusulas da fórmula podem se inverter, enfeiando até as palavras e tornando mesmo opaco o olhar da amada (futuro).

\section{Monte Parnaso}

Nos sonetos de Manuel Botelho de Oliveira, a confluência temporal, a que nos referimos, não parece gratuita. Ela se soma ao acúmulo de imagens que se cruzam ou se sobrepõem nos sonetos. Também a sonoridade é fator dos mais relevantes, tendo em vista o sugestivo título da obra: Música ("entoada" por um cantador) a partir do Parnaso, morada das musas e do Deus Apolo.

Deve-se recordar que Apolo também foi um dos temas recorrentes no Canzoniere de Franscesco Pretrarca, em que o poeta dedicou centenas de sonetos a Laura ("Laure", em italiano) - nome poético tirado de Laureta de Novaes, que de fato existiu e com quem ele conviveu.
Repare-se ainda uma vez que a temática do amor fugidio, associada ao tom angustiado assumido pelo eu-lírico, parece ter sido retomada (melhor dizendo, introjetada) pela persona poética criada por Manuel Botelho de Oliveira, reconhecido petrarquista e camoniano:

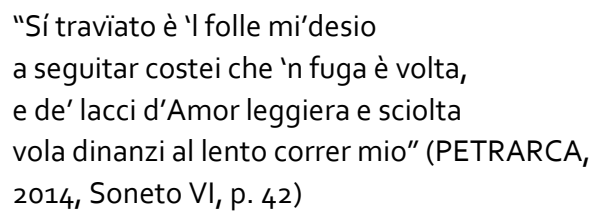

Seria improvável, senão impossível, negar os ecos da dicção de Petrarca em Música do Parnaso. De maneira absolutamente próxima ao poeta italiano, Manuel Botelho de Oliveira elege um nome para o qual dedicar várias formas poéticas, dentre as quais ressalta o soneto (gênero que praticamente domina o Cancioneiro petrarquiano).

A tópica do amor esquivo gira em torno de Anarda, musa de feições terrenas que em muito lembra Laura, figurada por Francesco Petrarca, com mais de dois séculos de precedência. A fidelidade aos modelos poéticos anteriores evidencia o fato de que a leitura dos versos do poeta baiano ganharia em muito se se considerasse o critério da autorictas, relacionada às "práticas antigas do discurso, como modelos anônimos mediatizados por categorias da Retórica" (HANSEN, 1992, p. 15).

\section{Som como Imagem}

Para além da obediência à tradição, outro aspecto a se considerado diz respeito à musicalidade sugerida pela poesia de Botelho de Oliveira. A leitura, não exclusiva, dos sonetos do primeiro coro de rimas mostra que, ao compor os seus versos, o poeta alterna vogais e consoantes, como se estivesse a reproduzir em termos 


\section{opiniães}

eufônicos a ambivalência dos sentidos emprestados às palavras, simultaneamente à oscilação do que sente e pensa, diante de Anarda, aquela que equivale a "dois maios", "dois sóis", de olhos "luzentes", mas "esquivos".

Esse jogo sonoro, favorecido pela alternância dos sons, cunhados sob mesma métrica e ritmo, comparece tanto nos sonetos de Petrarca (em que o nome de Laura participa da composição estrutural dos sonetos), quanto na lírica camoniana, como revelam os versos seguintes:

Os dias, na esperança de um só dia, Passava, contentando-se com vê-la; Porém o pai, usando de cautela, Em lugar de Raquel lhe dava Lia (CAMÕES, 1963, p. 106)

[ou]

\author{
Um encolhido ousar; uma brandura; \\ Um medo sem ter culpa; um ar sereno; \\ Um longo e obediente sofrimento: \\ Esta foi a celeste formosura \\ Da minha Circe, e o mágico veneno-amor \\ Que pôde transformar meu pensamento \\ (Idem, p. 107)
}

Na mesma chave, quando o poema de Manuel Botelho de Oliveira trata de elementos ligados à candura - invariavelmente sob a ótica da desrazão e a premissa dos afetos - com frequência enfileiram-se palavras de sonoridade adequada ao efeito pretendido, como se vê nas vogais nasais a traduzir mansidão:

Considera no sol, que luminoso Ama o jardim de flores guarnecido" (Soneto
Enfim dando ao jardim e ao céu demaios, O céu ostenta um sol, dous sóis Anarda, Um maio o jardim logra; ela dous maios (Soneto $X$ )

Esse vínculo, Anarda, luminoso, Do mínimo jasmim prisão dourada (Soneto XIV)

Outras vezes, o efeito buscado é um tanto diverso. Neles, Botelho visa a traduzir a alternância de estados da persona poética entre a angústia, a dureza, a condição agreste de seu espírito e a esperança de conquistar o amor que o "eu" deseja:

Se és dura rocha no rigor impio, Se és brilhadora luz na fronte amen; A triste chuva de cristais serena, Da sucessiva prata embarga o rio" (Soneto III)

"Porém para favor dos meus sentidos Essas folhas castiguem rigorosas, Os teus olhos, Anarda, os meus gemidos" (Soneto XI)

Atente-se, também, para o papel assumido pelos sons vocálicos. Ao alternar as vogais abertas com as médias ou fechadas, muitos versos parecem reproduzir, na sonoridade, o movimento constante entre a alegria e a tristeza; entre a expectativa e a frustração; entre o peito aberto e os olhos cerrados. Eis uma das imagens mais frequentes nos sonetos de Manuel Botelho de Oliveira:

Quando em mágoas me vejo atribulado, Vem sono, a meu desvelo padecido, 
Refrigera os incêndios do sentido, Os rigores suspende do cuidado (Soneto XIII)

Se te aprisiona seu favor lustroso,

Te retrata os efeitos de adorada;

Porque quando te adorna a luz amada,

Me aprisionas o peito venturoso (Soneto XIV)

Sem perder de vista essas breves sugestões de cunho estético, note-se que elas se somam à temática anunciada pelo título do livro. Especialmente por isso, não se pode desprezar a referência à morada dos deuses evidenciada pelo próprio Botelho de Oliveira, logo nos primeiros parágrafos de sua "Dedicatória".

Também nesse sentido, e em orientação oposta ao que sugere uma parte de nossa crítica mais tradicional, vale lembrar que Manuel Botelho de Oliveira era um fidalgo, tendo se bacharelado em Direito na Universidade de Coimbra, onde foi colega de Gregório de Matos e Guerra.

Homem poderoso, diretamente ligado à administração portuguesa, foi um Capitão-Mor de mentalidade lusitana, senhoril e católica, com boas relações na corte portuguesa, o que provavelmente favoreceu que obtivesse a licença de evocar figuras da antiga mitologia latina, ao compor as rimas de Música do Parnaso, a evocar o tempo, o lugar e a postura de Apolo. ${ }^{10}$

Esse dado parece ser muito relevante e produtivo, uma vez que a persona poética fala do alto, vinculando o estilo do que escreve ao lugar elevado (monte Parnaso) e ao tema sublime (a natureza, o amor, a beleza extrema).

Isso não quer dizer que houvesse arrogância ou altivez da parte da persona lírica inventada, ou, o que seria pior ainda, não nos permite julgar os versos pressupondo fatuidade e preciosismo do próprio Manuel Botelho de Oliveira.
Pelo contrário, ao referir-se ao Parnaso, morada dos deuses, reforça o entre-lugar do eu-lírico, cujas esperanças e lamentos sugerem o seu posicionamento como um ser radicalmente dividido entre a retidão apolínea e a sinuosidade do sentimento amoroso.

É o que se verifica em diversos momentos. A lágrima do homem e o veneno da serpente guardam em comum a característica de serem líquidas ("licores"), um vital, outro peçonha. Percorrendo os caminhos como se não tivesse rumo, o "coração queixoso" se move feito a "Serpe", "com passos mais oblíquos, que serenos" (Vendo a Anarda depõe o sentimento, p. 16). Claro esteja que "depor o sentimento" se traduz tanto pelo choro-sofrimento quanto pela inoculação do veneno-amor.

Transparência e opacidade. Para ressaltar os gritantes contrastes entre o que se sente e o que se repele, em "Cega duas vezes", vendo a Anarda, o eu-lírico contrapõe os "sóis abrasadores" de Anarda aos olhos sofredores "de águas sucessivas", dicotomia anunciada na estrofe seguinte, em que "resplandores" rima com "desfavores". (p. 17)

Costumeiramente, Anarda guarda equiparações com elementos ou fenômenos da natureza. O nono soneto (Rigores de Anarda na ocasião de um temporal), desenha-se de modo terrível, com direito a "ventos duplicados" e relâmpagos ("setas de prata despedidas"), devido à fúria do céu. A seu turno, Anarda despreza os tormentos alheios, lançando "Os raios dos rigores contra as vidas" e "As nuvens dos desdéns contra os cuidados" (p. 17).

Eis-nos trazidos novamente em presença da figura de olhar esquivo, a sintetizar as muitas formas com que a amada recusa ou se desvia frente aos sentimentos, preocupações e palavras doces do eu-lírico: "Em ti já 


\section{opiniães}

vejo a Anarda, ó Tejo esquivo" (Ponderação do Tejo com Anarda, p. 20); "teus desdéns esquivos" (Anel de Anarda ponderado, p. 21).

No entanto, a breve ira vem a ser constantemente contrabalançada pela constância e a intensidade do que ele sente, o que o leva a sugerir que "O céu ostenta um sol, dous sóis Anarda" (Ponderação do rosto e olhos de Anarda, p. 18); "Que a rosa deve ao sol seu luzimento,/O sol seu luzimento a Anarda deve" (Rosa, e Anarda, p. 26)

Mas o amor não se limita a sobrevalorizar a imagem da figura feminina. Repitamos: ao compor seus versos, Manuel Botelho de Oliveira aplica as lições constantes de diversos manuais que circulavam em seu tempo, como aquele de Manuel Pires de Almeida (1597-1655) que, colado a Horácio, afirmava que "as mesmas regras e os mesmos preceitos têm a pintura que a poesia [...], mas sem dúvida é indústria e natureza, arte e engenho o que os inclina a estas duas faculdades nascidas de um mesmo ventre e de um mesmo parto" (ALMEIDA, 2002, p. 75).

Ainda que determinadas escolhas representem a eternalização de seu martírio, o eu-lírico deseja representar sua amada em pedra, como se a equiparar a extensão do que sente com a memória imortal de Anarda: "Para esculpir a estátua imaginada,/ Logo derrete o bronze lagrimoso" (Anarda esculpida no coração lagrimoso, p. 22)

Ora, amar também significa sentir-se morto em vida, o que aproxima Manuel Botelho de Oliveira da melhor tradição da poesia lírica: "Anarda própria me deseja a morte,/ Anarda própria me defende a vida" (Efeitos contrários do rigor de Anarda, p. 24).

Na sua poesia, o amor e a morte estão em conflito cons- herdeiro da estética greco-latina, quanto aproximá-lo da lírica trovadoresca franco-portuguesa, quanto da poesia de inspiração neoplatônica de Petrarca e Camões, sem esquecer os sonetos de Shakespeare e o estilo de Gôngora.

Esse panteão de filósofos e versejadores que o antecederam, ao longo dos séculos, por si só assegura a intenção de emular a poesia dos melhores. Além disso, o fato de seguir e respeitar a tradição, em acordo com os preceitos e concepções em sua época revela o fato de sua obra ser firmemente orientada por modelos poéticos de outros tempos e lugares, que não o nosso, pretensamente original e alocado em vários lugares ao mesmo tempo.

Reconhecer a filiação de Manuel Botelho de Oliveira à melhor tradição do gênero lírico para além do universo ibérico, inclusive, constitui uma atitude sábia. Esse passo (essencial) deve ser o primeiro para que se proceda a uma efetiva reavaliação - certamente positiva de sua obra - e, consequentemente, para a (re)validação de outros poetas do mesmo período em que ele viveu. vamos a eles.

\section{Referências Bibliográficas}

ALMEIDA, Manuel Pires de. Poesia e pintura ou pintura e poesia. Edição preparada por Adma Fadul Muhana. Tradução João Ângelo Oliva Neto. São Paulo: Edusp; Fapesp, 2002.

ANDRADE, Mário de. Obra imatura (Há uma gota de sangue em cada poema; Primeiro andar; A escrava que não era Isaura). $3^{\mathrm{a}}$ ed. Belo Horizonte: Itatiaia, 1980.

ARISTÓTELES; HORÁCIO; LONGINO. A poética clássica. $15^{a}$ 


\section{opiniães}

ed. Tradução Jaime Bruna. São Paulo: Cultrix, 2010.

BOSI, Alfredo. "Botelho de Oliveira". In: História concisa da literatura brasileira. 39a ed. São Paulo: Cultrix, 2001.

CAMÕES, Luís Vaz de. Lírica. São Paulo: Cultrix, 1963.

CANDIDO, Antonio. Iniciação à literatura brasileira (resumo para principiantes). São Paulo: FFLCH: Humanitas, 1997.

GOMES, Eugênio. "A infanta e o javali". In: Visão e revisão. Rio de Janeiro: INL; MEC, 1958.

GRACIÁN, Baltasar. Arte de ingenio, tratado de la agudeza. $2^{\mathrm{a}}$ ed. Madrid: Ediciones Cátedra, 2010.

HANSEN, João Adolfo. "Autor". In: JOBIM, José Luis. Palavras da crítica. Rio de Janeiro: Imago, 1992.

Fênix renascida \& Postilhão de Apolo: uma introdução. In: PÉCORA, Alcir (Org.). Poesia seiscentista. São Paulo: Hedra, 2002.

MERQUIOR, José Guilherme. De Anchieta a Euclides: breve história da literatura brasileira. 3a ed. Rio de Janeiro: Topbooks, 1996.

MUHANA, Adma Fadul. "Introdução". In: Poesia completa: música do Parnasso, Lira sacra (Manuel Botelho de Oliveira). São Paulo: Martins Fontes, 2005.

NASCENTES, Antenor. "Prefácio". In: OLIVEIRA, Manuel Botelho de. Música do Parnaso. Tomo I. Rio de Janeiro: Instituto Nacional do Livro, 1953.

PETRARCA, Francesco. Cancioneiro. Tradução José Clemente Pozenato. Cotia (SP): Ateliê Editorial; Campinas (SP): Editora da Unicamp, 2014 [Versão bilíngue].
PONTE, Pero da. "Se eu pudesse desamar". In: MONGELLI, Lênia Márcia. Fremosos cantares (antologia da lírica medieval galego-portuguesa). São Paulo: WMFMartins Fontes, 2009.

TEIXEIRA, Ivan Prado. "A poesia aguda do engenhoso fidalgo Manuel Botelho de Oliveira". In: OLIVEIRA, Manuel Botelho de. Música do parnaso. Cotia (SP): Ateliê Editorial, 2005.

VERNEY, Luís António. Verdadeiro método de estudar (cartas sobre retórica e poética). Portugal: Editorial Presença, 1991.

\section{Notas}

1 (Se eu podesse desamar) In: Lênia Márcia Mongelli, Fremosos cantares, 2009, p. 19. 2 (Soneto III) In: Cancioneiro [Canzoniere], 2014, p. 40.

3 (Quem vê, Senhora, claro e manifesto) In: Lírica, 1963, p. 108.

4 "É a analogia, ou antes "o demônio da analogia" em que soçobrou Mallarmé. Mas a irmã bastarda da analogia a perífrase, parece-se muito com ela. A diferença está em que a analogia é subconsciente e a perífrase uma intelectualização exagerada, forçada, pretenciosa. É preciso não voltar a Rambouillet! É preciso não repetir Gongora É PRECISO EVITAR MALLARMÉ!" (ANDRADE, 1980, p. 240).

5 "(...) era pouco nítida a fronteira entre 'sábio' e 'pedante', pois o mesmo pedantismo alegado pejorativamente para constituir a inferioridade de muitos era efetivamente incentivado na formação de todos os letrados. Desde o colégio até à Universidade, os estudos feitos segundo os preceitos do Ratio studiorum da Companhia de Jesus previam justamente a memorização e a repetição de saberes tradicionais como fórmulas ético-políticas exemplares em todas as circunstâncias da vida de relação" (HANSEN, 2002, p. 41). Para Ivan Teixeira, ainda sobrevive a "convicção de que a poesia contribui para o mau gosto do leitor e seu afastamento da realidade imediata dos fenômenos dignos de imitação artística, que, basicamente, seriam a emoção pessoal, os embates da vida em sociedade e a relação do indivíduo com os valores responsáveis pela formação da nacionalidade" (TEIXEIRA, 2005, p. 36-47).

6 Essa passagem também chamou a atenção de Ivan Teixeira (2005), que, em seu estudo sobre a obra de Manuel Botelho de Oliveira, apresentou importantes ressalvas a consideração de Antonio Candido.

7 Refiro-me a "A infanta e o javali", incluído por Eugênio Gomes em seu Visões e 


\section{opiniães}

Revisões. Rio de Janeiro: MEC; INL, 1958.

8 "Como se sabe, a noção de variedade pressupõe a ideia de padrão. Básico na poética cultural dos Seiscentos, tal preceito se encontra sintetizado na Arte Poética de Horácio. Aí, a doutrina recomenda que, em lugar de inventar novos caracteres, o poeta deve limitar-se aos consagrados pelo costume" (TEIXEIRA, 2005, p. 59-60).

9 "a lírica se destina (...) a cantar seja a beleza, o bem amoroso, a amada, seja os homens virtuosos cujos feitos são dignos de se guardar na memória" (MUHANA, 2005, p. XXXVIII).

$10 \mathrm{~A}$ julgar pela desfaçatez e o modo perfeitamente à vontade com que Luís António Verney se referia à poesia "barroca", talvez suas palavras representassem boa parte da concepção de "literatura", segundo a crítica luso-brasileira, no século XVIII: "Nunca pude sofrer um poeta, no princípio de um poema moderno, invocar as Musas e Apolo para the inspirarem os pensamentos (...). Nós temos na nossa religião coisas que podem suprir a todas as ideias dos antigos" (VERNEY, 1991, p. 140). 